\section{Choroidal blood flow and arterial blood pressure}

\author{
K Polak ${ }^{1,2}$, E Polska ${ }^{2}$, A Luksch ${ }^{1,2}$, G Dorner $^{1,2}$, \\ G Fuchsjäger-Mayrl' ${ }^{1,2}$, O Findl ${ }^{1}$, H-G Eichler ${ }^{2}$, \\ $\mathrm{M}$ Wolzt $^{2}$ and L Schmetterer ${ }^{2,3}$
}

${ }^{1}$ Department of Ophthalmology Währinger Gürtel 18-20 A-1090 Vienna Austria

${ }^{2}$ Department of Clinical Pharmacology Währinger Gürtel 18-20 A-1090 Vienna Austria

${ }^{3}$ Institute of Medical Physics Währinger Straße 13 A-1090 Vienna Austria

Correspondence:

Dr Schmetterer

Institute of Medical Physics Währinger Straße 13 A-1090 Vienna Austria

Tel: + 431427760701

Fax: +43142779607

E-mail:

Leopold.Schmetterer@ univie.ac.at

Received: 30 July 2001 Accepted: 4 April 2002

\begin{abstract}
Purpose Untreated hypertension is associated with ocular complications and is a risk factor for the development and progression of vascular ocular pathologies. We set out to investigate the association between systemic blood pressure and choroidal blood flow.

Methods All subjects were male nonsmokers, who did not receive any medication and had normal or slightly elevated blood pressure (systolic blood pressure $\leq 160 \mathrm{mmHg}$; diastolic blood pressure $\leq 100 \mathrm{mmHg}$ ). The association between systemic blood pressure and fundus pulsation amplitude, a measure of pulsatile choroidal blood flow, was investigated in 318 volunteers. In addition, the association between systemic blood pressure and blood flow velocities in the posterior ciliary arteries supplying the choroid was investigated in these subjects.

Results Ocular fundus pulsation amplitude $(r=0.252 ; P<0.001)$ and mean flow velocity in the posterior ciliary arteries $(r=0.346$, $P<0.001)$ were significantly associated with mean arterial pressure. The correlation of ocular haemodynamic variables with systolic and diastolic blood pressure was in the same range.

Conclusions Our data indicate a small, but significant increase in choroidal blood flow with increasing blood pressure.

Eye (2003) 17, 84-88. doi:10.1038/

sj.eye. 6700246
\end{abstract}

Keywords: choroidal blood flow; fundus pulsation; Doppler sonography; hypertensive retinopathy

\section{Introduction}

Hypertensive retinopathy is a common ocular complication of untreated systemic hypertension. ${ }^{1,2}$ When blood pressure is adequately controlled hypertensive retinopathy is normally not seen, ${ }^{1}$ which indicates that these structural alterations are closely linked to an abnormally elevated ocular perfusion pressure.

However, there are little data available on the effect of systemic hypertension on choroidal perfusion in humans, which may be related to the difficulties in assessing blood flow in this vascular bed. Laser Doppler flowmetry measures choroidal blood flow in relative units. ${ }^{3}$ Inter-group comparison of such data is hampered, because absolute flow values as measured with laser Doppler flowmetry strongly depend on the scattering properties of the surrounding tissue and the specific angioarchitecture, which is subject to high interindividual variation. ${ }^{4}$

In the present study we therefore used two alternative methods to investigate the association between choroidal haemodynamics and systemic blood pressure. Pulsatile choroidal blood flow was assessed using laser interferometric measurement of fundus pulsation. ${ }^{5}$ In addition, blood flow velocities in the posterior ciliary arteries supplying the choroid were measured with colour Doppler imaging. ${ }^{6}$ The study was performed in male subjects with either normal blood pressure or mild untreated hypertension.

\section{Materials and methods}

\section{Subjects}

After ethics committee approval, 318 male nonsmoking volunteers in the age range between 19 and 40 years with a systolic blood pressure (SBP) $\leq 160 \mathrm{mmHg}$ and a diastolic blood pressure (DBP) $\leq 100 \mathrm{mmHg}$ were studied. All subjects were drug free for at least 3 weeks and did not use any regular medication. All subjects gave written consent to participate. Each subject passed a screening examination that included medical history and physical examination, 12lead electrocardiogram, complete blood count, activated partial thromboplastin time, thrombin time, fibrinogen, clinical chemistry (sodium, potassium, creatinine, uric acid, glucose, 
cholesterol, triglycerides, alanine aminotransferase, aspartate aminotransferase, $\gamma$-glutamyltransferase, alkaline phosphatase, total bilirubin, total protein), hepatitis A, B, C and HIV-serology, urine analysis, and a random urine drug screen. Furthermore, an ophthalmic examination, including slit lamp biomicroscopy and indirect funduscopy, was performed. Inclusion criteria were normal laboratory values, normal ophthalmic findings and a refractive error of less than 3 dioptres in either eye. In all subjects the right eye was studied.

\section{Study design}

For all subjects a resting period of at least 20 min was scheduled. After stable haemodynamic conditions were reached, which was verified by repeated blood pressure measurement, ocular fundus pulsation, blood velocities in the posterior ciliary arteries, blood pressure, and pulse rate were measured.

\section{Study methods}

Blood pressure and pulse rate SBP, DBP and mean blood pressures (MAP) were measured on the upper arm by an automated oscillometric device (HP-CMS patient monitor, Hewlett Packard, Palo Alto, CA, USA). Pulse pressure amplitude (PPA) was calculated as SBP-DBP. In analogy to the ultrasound measure resistive index a blood pressure index (BPI) was calculated as BPI = (SBP-DBP)/SBP.7 Pulse rate was automatically recorded from a finger pulse oxymetric device (HP-CMS patient monitor).

Fundus pulsation Pulse synchronous pulsations of the eye fundus were assessed by laser interferometry in the subject's right eye. The method is described in detail by Schmetterer et al. ${ }^{8}$ Briefly, the eye is illuminated by the beam of a single mode laser diode with a wavelength $(\lambda)$ of $783 \mathrm{~nm}$. The light is reflected at both the front side of the cornea and the retina. The two re-emitted waves produce interference fringes, which allow the calculation of the distance changes between cornea and retina during a cardiac cycle. Distance changes between cornea and retina lead to a corresponding variation of the interference order $(\Delta N(t))$. This change in interference order can be evaluated by counting the fringes moving inwards and outwards during the cardiac cycle. Changes in optical distance $(\Delta L(t))$, corresponding to the cornearetina distance changes, can then be calculated by $\Delta L(t)=\Delta N(t) \lambda / 2$. The maximum distance change is called the fundus pulsation amplitude (FPA) and estimates the local pulsatile blood flow. ${ }^{5}$ FPA was calculated as the mean of at least five cardiac cycles. To obtain information on the choroidal blood flow, the macula, which lacks retinal vasculature, was chosen for measurements.

Doppler sonography Mean blood flow velocity (MFV), peak systolic flow velocity (PSV), and end diastolic flow velocity (EDV) were determined in the right posterior ciliary arteries with colour Doppler imaging as described in detail elsewhere. ${ }^{6}$ MFV was measured manually as time mean of the spectral outline. Measurements were performed with a $7.5 \mathrm{MHz}$ probe (CFM 750, Vingmed Sound, Horten, Norway). The resistive index in the posterior ciliary arteries was calculated as $\mathrm{RI}=(\mathrm{PSV}-\mathrm{EDV}) / \mathrm{PSV}$. All parameters were determined as mean values over at least three cardiac cycles.

\section{Data analysis}

All statistical analyses were done using the Statistica ${ }^{\circledR}$ software package (Release 4.5, StatSoft Inc., Tulsa, OK, USA). The association between ocular and systemic haemodynamic parameters was investigated using linear correlation analysis. Multiple regression analysis was performed to determine correlations between ocular haemodynamic parameters and the other variables. Data are presented as means \pm s.d. A two-tailed $P<0.05$ was considered the level of significance.

\section{Results}

Subjects' characteristics are shown in Table 1. The association between ocular haemodynamic and systemic haemodynamic variables is presented in Figures 1 to 3. Ocular FPA was associated with SBP, DBP and MAP $(P<0.001$ each). By contrast, the correlation of FPA with PPA was not significant. Mean flow velocity in the posterior ciliary arteries was also correlated with SBP, DBP, and MAP $(P<0.001)$, but not with PPA (data not shown). By contrast, RI in the

Table 1 Subjects characteristics

\begin{tabular}{lc}
\hline Age (years) & $27.6 \pm 4.9$ \\
Systolic blood pressure $(\mathrm{mmHg})$ & $132.2 \pm 12.9$ \\
Diastolic blood pressure $(\mathrm{mmHg})$ & $70.5 \pm 13.1$ \\
Mean arterial pressure $(\mathrm{mmHg})$ & $91.1 \pm 12.7$ \\
Pulse rate (beats/min) & $64.9 \pm 7.9$ \\
Fundus pulsation amplitude $(\mu \mathrm{m})$ & $4.3 \pm 1.0$ \\
Mean flow velocity $(\mathrm{cm} / \mathrm{s})$ & $6.4 \pm 0.8$ \\
Resistive index & $0.70 \pm 0.04$
\end{tabular}

Data are presented as means \pm s.d. $(n=318)$. 

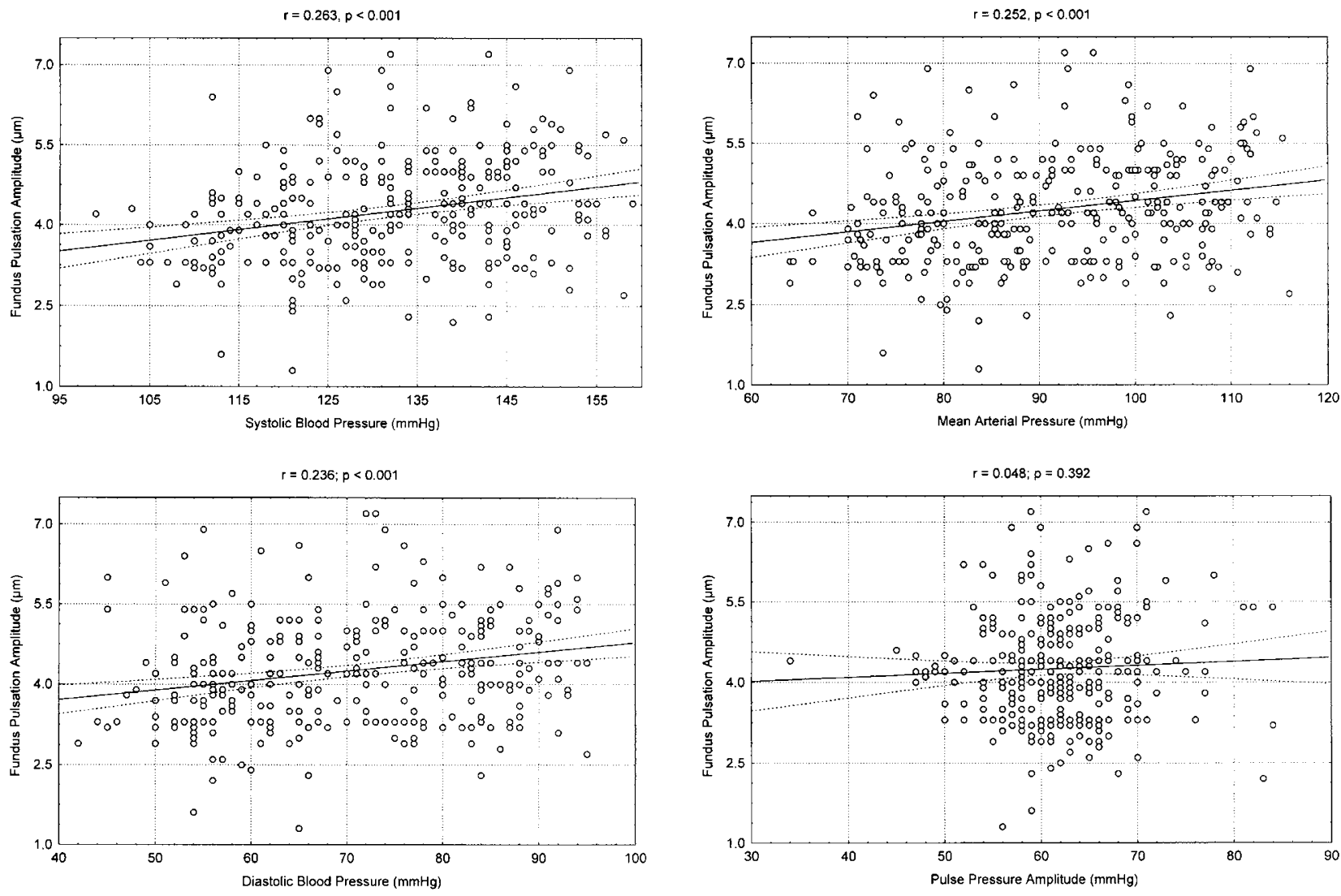

Figure 1 Association between fundus pulsation amplitude and systolic blood pressure (upper left panel), diastolic blood pressure (lower left panel), mean arterial pressure (upper right panel), and pulse pressure amplitude (lower right panel). The regression line and the $95 \%$ confidence interval are shown $(n=318)$.

posterior ciliary arteries was not associated with SBP, DBP, or MAP, but showed a significant correlation with BPI $(P<0.001)$. None of the ocular haemodynamic variables was associated with pulse rate (data not shown).

The results of the multiple regression analysis are presented in Table 2. In accordance with the results of the linear regression analysis, we observed a significant correlation of FPA and mean flow velocity in the posterior ciliary arteries with SBP, DBP, and MAP. Both variables tended to decline with age, but none of these correlations reached the level of significance.

Table 2 Multiple regression analysis between ocular haemodynamic parameters, blood pressure, pulse rate and age

\begin{tabular}{lcc}
\hline & $\begin{array}{l}\text { Fundus pulsation } \\
\text { amplitude }\end{array}$ & $\begin{array}{l}\text { Mean flow } \\
\text { velocity }\end{array}$ \\
\hline Age & 0.062 & 0.092 \\
Systolic blood pressure & 0.001 & 0.001 \\
Diastolic blood pressure & 0.001 & 0.001 \\
Mean arterial pressure & 0.001 & 0.001 \\
Pulse rate & 0.322 & 0.634 \\
\hline
\end{tabular}

\section{Discussion}

The present study indicates that choroidal blood flow slightly increases with blood pressure. We observed that fundus pulsation amplitude increases by approximately $5 \%$ per $10 \mathrm{mmHg}$ increase in MAP. Likewise, mean flow velocity in the posterior ciliary arteries increases by approximately $3.5 \%$ per $10 \mathrm{mmHg}$ increase in MAP. Is this small increase of choroidal blood flow with increasing blood pressure of clinical relevance? It is currently not known what degree of overperfusion is detrimental for the eye. However, there is evidence that in healthy subjects choroidal blood flow is autoregulated over a wide range of perfusion pressures, ${ }^{9,10}$ which indicates that physiologically choroidal blood flow is almost constant. In patients without or with early stage diabetic retinopathy, the increase in ocular blood flow is only $10-20 \% .{ }^{11-13}$ Hence, even small hypertensioninduced changes in ocular blood flow may put the patient at additional risk for progression of diabetic retinopathy. It has been hypothesized that these small elevations in ocular perfusion may cause endothelial damage and dysfunction, ${ }^{14}$ which is observed in patients 


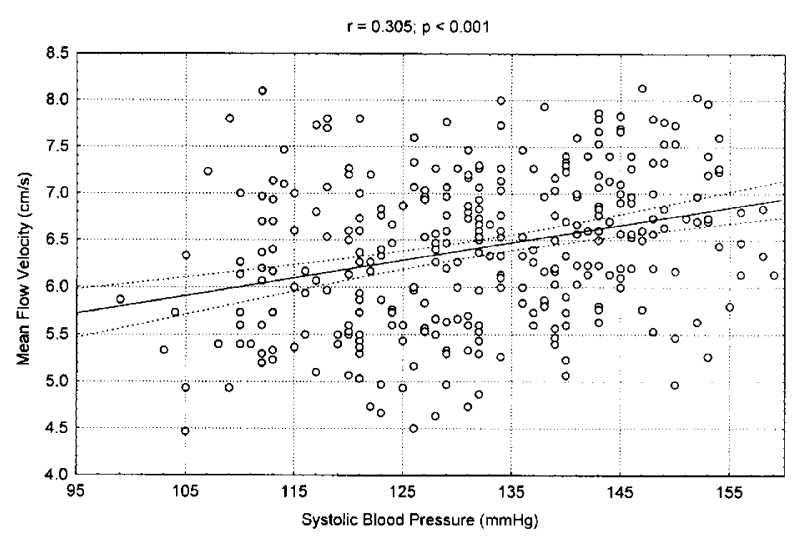

$r=0.352: p<0.001$

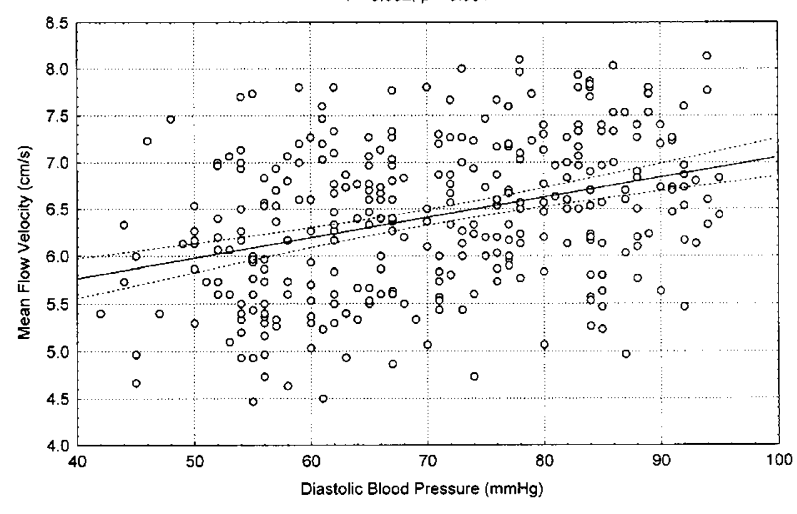

$r=0.346 ; p<0.001$

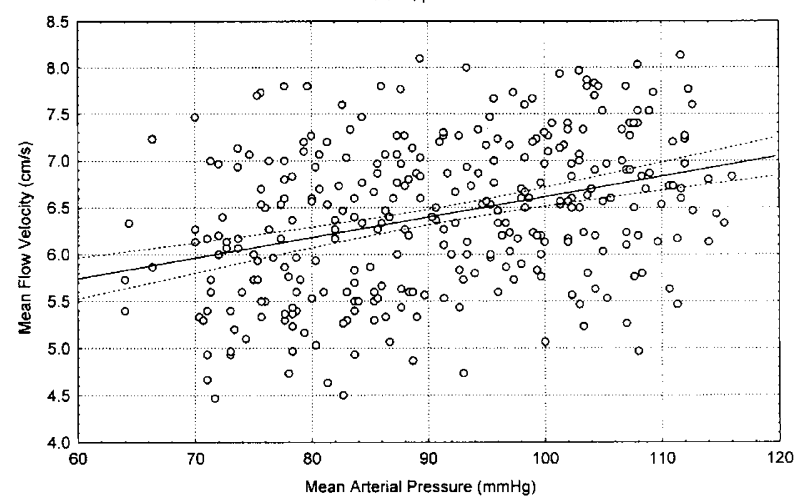

Figure 2 Association between mean flow velocity in the posterior ciliary arteries and systolic blood pressure (first panel), diastolic blood pressure (second panel), and mean arterial pressure (third panel). The regression line and the 95\% confidence interval are shown $(n=318)$.

with type 1 diabetes at the level of the ocular blood vessels. ${ }^{15}$

In the present study we focused on young male subjects, because ocular blood flow declines with increasing age $\mathrm{e}^{16-18}$ and little information on sex differences in ocular blood flow is available. In our study cohort of subjects aged less than 40 years we did not observe a significant association between age and the ocular haemodynamic parameters although a tendency was seen. In a previous study it has been observed that
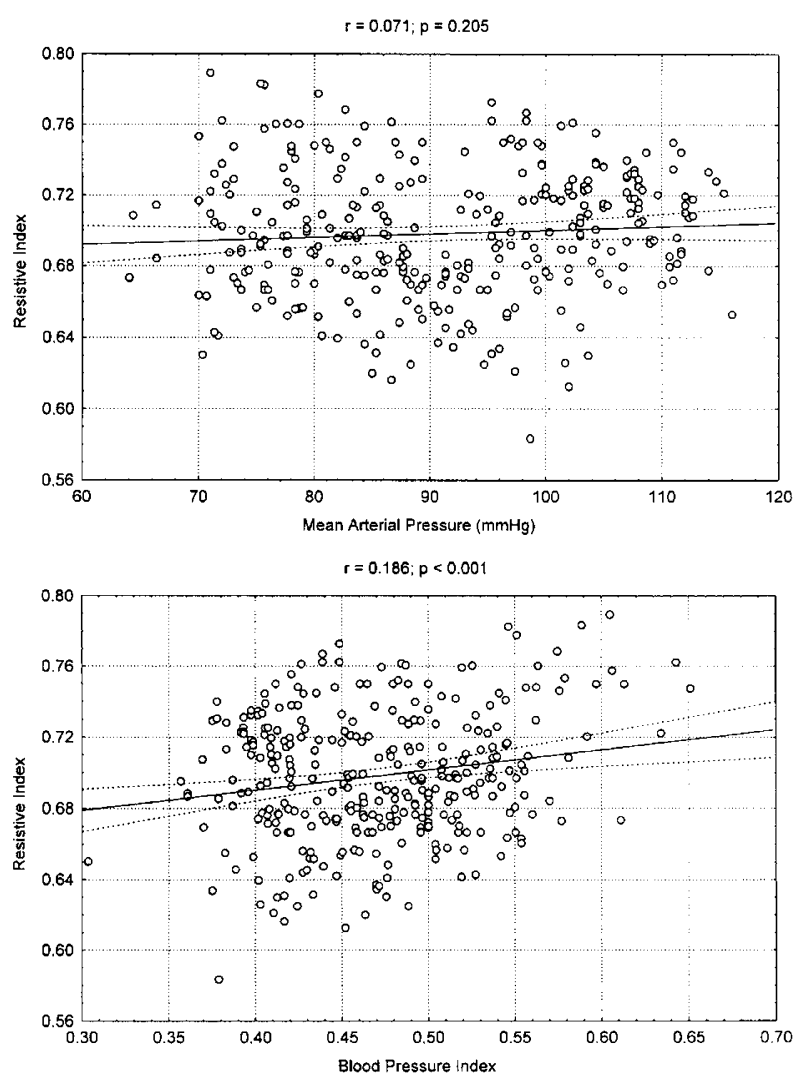

Figure 3 Association between resistive index in the posterior ciliary arteries and mean arterial pressure (upper panel), and blood pressure index (lower panel). The regression line and the 95\% confidence interval are shown $(n=318)$.

age is weakly negatively correlated with blood velocities in the ophthalmic artery. ${ }^{19}$ Moreover, we studied subjects with mild untreated hypertension, because any form of anti-hypertensive medication may affect ocular blood flow. ${ }^{20-22}$ Finally, we focused on subjects with $\mathrm{SBP} \leq 160 \mathrm{mmHg}$ and $\mathrm{DBF} \leq 100 \mathrm{mmHg}$ based on the evidence that even mild hypertension may induce an additional risk for progression of diabetic retinopathy in patients with type 2 diabetes. ${ }^{23}$

Fundus pulsation as assessed with laser interferometry and blood velocities of retrobulbar vessels as measured with colour Doppler imaging do not provide a direct measure of choroidal blood flow. Fundus pulsation amplitude estimates the pulsatile component of choroidal blood flow, but no information on the steady component is obtained. It is not entirely clear which fraction of blood flow in the choroid is pulsatile.

Estimates vary between $50^{24}$ and $80 \%{ }^{25}$ Interestingly, the association between PPA, which is the driving force of pulsatile blood flow, and fundus pulsation amplitude in the present study was not significant. This indicates that ocular fundus pulsation is mainly influenced by local ocular factors, but not by the blood pressure profile. Nevertheless, we cannot entirely exclude that systemic 
hypertension may influence flow pulsatility in the choroid.

Colour Doppler imaging measures blood flow velocities in posterior ciliary arteries, but no quantitative information on vessel diameter is obtained. Hence, MFV data cannot necessarily be extrapolated to blood flow through these arteries. Interestingly, resistive index in the posterior ciliary arteries was not dependent on MAP, SBP or DBP, but was significantly associated with BPI. This is compatible with our previous findings ${ }^{7}$ and indicates that blood pressure profile is a determinant of resistive index in the posterior ciliary arteries, which should be taken into account when patients with different ocular pathologies are compared. In a previous study, flow velocities in the posterior ciliary arteries were not correlated with blood pressure. ${ }^{26}$ However, these authors included subjects aged between 7 and 78 years and found a significant impact of age on flow velocities in the lateral posterior ciliary arteries. Hence, comparison with the present data is difficult.

In conclusion, our data indicate a small, but significant increase in choroidal blood flow with increasing blood pressure.

\section{References}

1 Schubert HD. Ocular manifestations of systemic hypertension. Curr Opin Ophthalmol 1998; 9: 69-72.

2 Sharp PS, Chaturvedi N, Wormald R, McKeigue PM, Marmot MG, Young SM. Hypertensive retinopathy in AfroCaribbeans and Europeans. Prevalence and risk factor relationships. Hypertension 1995; 25: 1322-1325.

3 Riva CE, Petrig BL. Choroidal blood flow by laser Doppler flowmetry. Opt Eng 1995; 34: 746-752.

4 Hayreh SS. In vivo choroidal circulation and its watershed zones. Eye 1990; 4: 273-289.

5 Schmetterer L, Dallinger S, Findl O, Schmetterer K, Lexer F, Eichler HG et al. A comparison between laser interferometric measurement of fundus pulsation and pneumotonometric measurement of pulsatile ocular blood flow. 1. Baseline considerations. Eye 2000; 14: 39-45.

6 Lieb WE, Cohen SM, Merton DA, Shields JA, Mitchell DG, Goldberg BB. Color Doppler imaging of the eye and the orbit. Arch Ophthalmol 1991; 109: 527-531.

7 Krejcy K, Wolzt M, Kreuzer C, Breiteneder H, Schütz W, Eichler HG et al. Characterization of Angiotensin-II effects on cerebral and ocular circulation by noninvasive methods. Br J Clin Pharmacol 1997; 43: 501-508.

8 Schmetterer L, Lexer F, Unfried C, Sattmann H, Fercher A. Topical measurement of fundus pulsations. Opt Eng 1995; 34: 711-716.
9 Riva CE, Titze P, Hero M, Movaffaghy A, Petrig BL. Choroidal blood flow during isometric exercises. Invest Ophthalmol Vis Sci 1997; 38: 2338-2343.

10 Riva CE, Titze P, Hero M, Petrig BL. Effect of acute decreases of perfusion pressure on choroidal blood flow in humans. Invest Ophthalmol Vis Sci 1997; 38: 1752-1760.

11 Grunwald JE, DuPont J, Riva CE. Retinal haemodynamics in patients with early diabetes mellitus. Br J Ophthalmol 1996; 80: 327-331.

12 MacKinnon JR, O'Brien C, Swa K, Aspinall P, Butt Z, Cameron D. Pulsatile ocular blood flow in untreated diabetic retinopathy. Acta Ophthalmol 1997; 75: 661-664.

13 Patel V, Rassam S, Newsom R, Wiek J, Kohner E. Retinal blood flow in diabetic retinopathy. Br Med J 1992; 305: 678-683.

14 Kohner EM, Patel V, Rassam SM. Role of blood flow and impaired autoregulation in the pathogenesis of diabetic retinopathy. Diabetes 1995; 44: 603-607.

15 Schmetterer L, Findl O, Fasching P, Ferber W, Strenn K, Breiteneder $\mathrm{H}$ et al. Nitric oxide and ocular blood flow in patients with IDDM. Diabetes 1997; 46: 653-658.

16 Dallinger S, Findl O, Strenn K, Eichler HG, Wolzt M, Schmetterer L. Age dependence of choroidal blood flow. J Am Ger Soc 1998; 46: 484-487.

17 Grunwald JE, Piltz J, Patel N, Bose S, Riva CE. Effect of aging on retinal macular microcirculation: a blue field simulation study. Invest Ophthalmol Vis Sci 1993; 34: 3609-3613.

18 Ravalico G, Toffoli G, Pastori G, Croce M, Calderini S. Age-related ocular blood flow changes. Invest Ophthalmol Vis Sci 1996; 37: 2645-2650.

19 Williamson TH, Lowe GD, Baxter CM. Influence of age, systemic blood pressure, smoking, and blood viscosity on orbital blood velocities. Br J Ophthalmol 1995; 79: 17-22.

20 Grunwald JE, DuPont J, Dreyer EB. Effect of chronic nitrate treatment on retinal vessel caliber in open-angle glaucoma. Am J Ophthalmol 1997; 123: 753-758.

21 Grunwald JE, Iannaccone A, DuPont J. Effect of isosorbide mononitrate on the human optic nerve and choroidal blood circulations. Br J Ophthalmol 1999; 83: 162-167.

22 Patel V, Rassam SM, Chen HC, Jones M, Kohner EM. Effect of angiotensin-converting enzyme inhibition with perindopril and beta-blockade with atenolol on retinal blood flow in hypertensive diabetic subjects. Metabolism 1998; 47 (Suppl 1): 28-33.

23 UKPDS. Tight blood pressure control and risk of macrovascular and microvascular complications in type 2 diabetes: UKPDS 38. UK Prospective Diabetes Study Group. Br Med J 1998; 317: 703-713.

24 Krakau CET. A model for pulsatile and steady ocular blood flow. Graefes Arch Clin Exp Ophthalmol 1995; 233: 112-118.

25 Langham ME, Farrell RA, O'Brien V, Silver DM, Schilder P. Blood flow in the human eye. Acta Ophthalmol 1989; 67 (Suppl. 191): 9-13.

26 Kaiser HJ, Schoetzau A, Flammer J. Blood-flow velocities in the extraocular vessels in normal volunteers. $A m \mathrm{~J}$ Ophthalmol 1996; 122: 364-370. 